\title{
Improving Emotion Regulation skills through an Emotional Intelligence Training Course
}

\author{
Zahra Bagheri \\ Universiti Teknologi Malaysia, Johor, Malaysia \\ Azlina Mohd Kosnin \\ Universiti Teknologi Malaysia, Johor, Malaysia \\ Mohammad Ali Besharat \\ University of Tehran, Iran
}

\section{Introduction}

In recent years, there has been considerable scientific interest in the research of emotion regulation in general mental-health and psychotherapy research. Gross (1998) defined emotion regulation as"the process by which individuals influence which emotions they have, when they have them, and how they experience and express these emotions ( p. 275)". Individuals regulate their emotions through these processes consciously and unconsciously (Bargh \& Williams, 2007; Rottenberg \& Gross, 2003) to respond environmental demands (Campbell-Sills \& Barlow, 2007; Cole, Martin, \& Dennis, 2004; Thompson, 1994). In another definition, emotion regulation is "the extrinsic and intrinsic processes responsible for monitoring, evaluating, and modifying emotional reactions, intensive and temporal features, to accomplish one's goals"' (Thompson, 1994, pp. 27-28).

Emotion Regulation is an essential aspect of psychological health. Gross and Muñoz (1995) found the association between emotion regulation and mental health. Additionally, some studies demonstrated the ability to regulate emotions to be related to academic achievement (Gumora \& Arsenio, 2002), improvement of relationships and work performance (Brackett \& Salovey, 2004; John \& Gross, 2004). In contrast, difficulties in emotion regulation are associated with greater distress (Mennin \& Farach, 2007; Nolen-Hoeksema, Wisco, \& Lyubomirsky, 2008), and a variety of problematic behaviors and mental disorders including substance use (Kun \& Demetrovics, 2010), depression (Gross \& John, 2003; John $\&$ Gross, 2004), and anxiety (Cisler, Olatunji, Feldner, \& Forsyth, 2010). The low 
level of emotion regulation also predicts various kinds of antisocial behaviors (Lotze, Ravindran, \& Myers, 2010). Some researchers claimed individuals who cannot effectively manage their emotional responses to the events that experience distress in the long periods, may evolve into diagnosable depression or anxiety (Nolen-Hoeksema, Wisco, \& Lyubomirsky, 2008).

One approach to emotion regulation is the emotional intelligence frameworkthat refers to the "ability to recognize the meanings of emotions and their relationships and to use them as a basis in reasoning, problem solving and enhancing cognitive activities" (Mayer, Salovey, Caruso, \& Sitarenios, 2001, p. 234).

Mayer \& Salovey (1997) introduced the ability model for emotional intelligence theory that involves four branches: perception emotion, understanding emotion, facilitation emotion to thought and emotion management. Several researchers showed that emotional intelligence has positive associations with life satisfaction, happiness, psychological health and social network size (Austin, Saklofske, \& Egan, 2005; Day, Therrien, \& Carroll, 2005; Furnham, \& Petrides, 2003). It has negative associations with stress, depression and loneliness (Palmer, Donaldson, \& Stough, 2002; Saklofske, Austin, \& Minski, 2003; Austin, Saklofske \& Egan, 2005), alcohol consumption and smoking among adults (Dawda \& Hart, 2000). Emotional intelligence is an important predictor of health and well-being (Martins, Ramalho, \& Morin, 2010).

Regarding to the research findings, emotion regulation as a component of emotional intelligence is an important predictor of mental health, social relationship, academic achievement and work performance. In addition, a number of neurological studies on brain-damage; suggesting that people must be able to use emotional information for rational decision-making and other cognitive processes in order to manage their lives (Damasio, 1994). Then, there is a compelling argument to make for teaching and training the emotion regulation in young peoples. They have a strong desire to establish social relationship, interpersonal skills and emotional adaptation to find job opportunities, gain higher education, get married and to meet standards of living. All these will not possible without acquiring the knowledge and skills needed in order to retain an occupational position, which gives them the senses of satisfaction and accomplishment. Students who cannot regulate their impulsive behavior and emotional reactions experience difficulties in adapting to school, the environments and conditions of the workplace, and to social milieu (Caspi, 2000; Eisenberg, Fabes, Guthrie, \& Reiser, 2000; Metcalfe \& Mischel, 1999) and lack of social competence (Denham \& Burton, 2003). 
There are a number of intervention programs to improve emotional regulation. Some of them try to address the clinical aspects of emotion regulation such as an emotion-regulation therapy (Mennin \& Fresco, 2009), and emotion focused therapy (Greenberg, 2002) which are more effective for patients with mental disorders. Further empirical studies are needed to examine the effectiveness of training emotional intelligence to improve emotion regulation in ordinary people.

The present study aimed to design and experiment an emotional intelligence training course (EITC) to improve emotion regulation. This program provided based on Mayer and Salovey's theory (1990).

\section{Method}

\subsection{Participants}

The participants were undergraduate students from a university in Iran. They came from different academic backgrounds, such as law, mechanical engineering, computer and civil engineering. They were a convenience sample because they should be volunteers and agree to be studied, but were randomly assigned to either the experimental or control group. A total of 60 participants were grouped into an experimental group $(n=30)$ and control group $(n=30)$. The experimental group consisted of 13 males and 17 females, with a mean age of 21.36 years ( $\mathrm{SD}=1.69)$, and the control group included of 12 males and 18 females with a mean age of 22.1 years $(\mathrm{SD}=2.07)$.

\subsection{Measure}

The emotional intelligence scale-41(EIS-41) that used in this study is a revised version of the 33-item emotional intelligence scale of Schutte et al. (1998) which was devised by Austin et al. (2004). They reported three factor structures in EIS41that measure individual's ability including the Optimism/Mood Regulation, Utilization of Emotions and Appraisal of Emotions in oneself and others. Besharat (2007) converted the emotional-intelligence scale - 41 to Farsi. The scale - 41 was translated into Farsi and back-translated by a research team with one psychologist and two Ph.D students of the English language. There was no substantial change in the content of the items in the Farsi version (Besharat, 2007). The findings reconfirmed the internal consistency, reliability, and concurrent validity of the scale-41 and showed that the Farsi version of the EIS-41 has sufficient internal consistency. The internal reliabilities of scales derived for the three factors 
(Regulation of Emotions, Utilization of Emotions, Appraisal of Emotions) were $0.83,0.78$ and 0.81 .

In this study, the reliability of the Farsi version (FEIS 41) using Cronbach's alpha was .88 which is similar to the original test (.85).

\subsection{Emotional Intelligence Training Course}

The emotional intelligence training course (EITC) of this study was constructed based on Mayer \& Salovey's ability model (1997) that includes the perception of emotion, understanding emotion, using emotion and managing emotion. The researchers of this study believe that in order to regulate emotions effectively, individuals should learn to perceive emotions in one and in others; then they should gain the necessary knowledge as to how to express it in a very constructive way. They also need to understand the causes and consequences of a wide range of complex emotions in order to be able to use them in cognitive activities. This matter also has been suggested by some researchers that mentioned emotion regulation is only possible after recognizing emotion because emotion recognition is conceptually more primary than emotion regulation (Izard, 2001; Lane, 2000; Mayer et al., 2001). In other research Szczygiel and his colleagues (2011) found that high emotional awareness can prevent the damage of negative emotions.

Emotional intelligence training course involved of six sessions of two and half hours. The six sessions were spread out within six weeks. There were two training groups; each one included 15 participants. During the interval between each session, the participants gathered their daily emotional experiences. They were asked to explain how that emotion affected their lives as well as others' with focus on emotional regulation (intrapersonal and interpersonal) and discuss about them in class. Short lectures, role plays and group discussions were the content of each session. The outline of the sessions is shown in the appendix A.

\subsection{Procedure}

All participants (experimental-control) completed the scale-41 twice: 1 week before to session 1 (time1), and one week after session 6 (time2). The participants in the experimental group received six session training but participants in the control group did not.

\section{Results}


Independent-samples t-test was examined to compare any baseline differences between the experimental and the control group before training (time1). There were no significant differences between two groups in the scores of independent variables in time1 (see Table 1).

Table1: Means, standard deviations and differences between experimental and control group before training (baseline)

\begin{tabular}{|l|l|l|l|l|}
\hline \multicolumn{1}{|c|}{ Variable } & \multicolumn{1}{|c|}{$\begin{array}{c}\text { Experimental } \\
\text { group } \\
\text { Mean(SD) }\end{array}$} & $\begin{array}{c}\text { Control group } \\
\text { Mean(SD) }\end{array}$ & t-value & Sig \\
\hline Emotion regulation & $39.433(4.724)$ & $37.800(5.591)$ & $\mathrm{t}(58)=1.22$ & .227 \\
\hline Emotion utilization & $24.166(2.829)$ & $24.066(3.768)$ & $\mathrm{t}(58)=.116$ & .908 \\
\hline Appraisal of emotion & $29.166(3.957)$ & $29.800(5.175)$ & $\mathrm{t}(58)=-.532$ & .596 \\
\hline EI total score & $1.436(9.463)$ & $1.394(13.497)$ & $\mathrm{t}(58)=1.407$ & .165 \\
\hline
\end{tabular}

Repeated measures MANOVA test was conducted to test the effect of training on improving EI. The results indicated that the experimental group had a significant increase in the emotion regulation, emotion utilization, appraisal of emotion and emotional intelligence score between pre and post-test. Descriptive statistics (means, standard deviation) for pre-test and post- test are presented in Table 2

Table 2: Means, standard deviations and differences between time 1 (pre-test) and time 2 (post-test)

\begin{tabular}{|c|c|c|c|c|c|}
\hline \multirow{2}{*}{ Variable } & \multicolumn{2}{|c|}{ Experimental } & \multicolumn{2}{c|}{ Control } & \multirow{2}{*}{ F-value } \\
\cline { 2 - 5 } & $\begin{array}{c}\text { Time1 } \\
\text { Mean(SD) }\end{array}$ & $\begin{array}{c}\text { Time2 } \\
\text { Mean(SD) }\end{array}$ & $\begin{array}{c}\text { Time1 } \\
\text { Mean(SD) }\end{array}$ & $\begin{array}{c}\text { Time2 } \\
\text { Mean(SD) }\end{array}$ & $\begin{array}{c}\text { Sig } \\
\text { Emotion Regulation }\end{array}$ \\
\cline { 2 - 5 } & $\begin{array}{c}39.43 \\
(4.72)\end{array}$ & $\begin{array}{c}43.96 \\
(3.48)\end{array}$ & $\begin{array}{c}37.80 \\
(5.59)\end{array}$ & $\begin{array}{c}36.86 \\
(5.21)\end{array}$ & $\begin{array}{c}38.45 \\
\mathrm{p}<.001\end{array}$ \\
\hline
\end{tabular}




\begin{tabular}{|c|c|c|c|c|c|}
\hline Emotion Utilization & $\begin{array}{c}24.16 \\
(2.82)\end{array}$ & $\begin{array}{c}30.50 \\
(1.99)\end{array}$ & $\begin{array}{c}24.06 \\
(3.76)\end{array}$ & $\begin{array}{c}24.40 \\
(4.15)\end{array}$ & $\begin{array}{c}52.49 \\
\mathrm{p}<.001\end{array}$ \\
\hline $\begin{array}{c}\text { Appraisal of } \\
\text { emotion }\end{array}$ & $\begin{array}{c}29.16 \\
(3.95)\end{array}$ & $\begin{array}{c}36.43 \\
(2.47)\end{array}$ & $\begin{array}{c}29.80 \\
(5.17)\end{array}$ & $\begin{array}{c}29.73 \\
(5.73)\end{array}$ & $\begin{array}{c}34.52 \\
\mathrm{p}<.001\end{array}$ \\
\hline EI total score & $\begin{array}{c}1.43 \\
(9.46)\end{array}$ & $\begin{array}{c}1.39 \\
(13.49)\end{array}$ & $\begin{array}{c}1.65 \\
(6.23)\end{array}$ & $\begin{array}{c}1.41 \\
(13.73)\end{array}$ & $\begin{array}{c}81.76 \\
\mathrm{p}<.001\end{array}$ \\
\hline
\end{tabular}

Repeated measures MANOVA tests also were carried out to measure any statistically significant changes with "time" as the within subject factor and "group" as the between subject factor. Pillai's Trace is one of these analyses that show the multivariate outcome across each independent variable and also an interaction between them. The results showed that there was a significant multivariate effect for between subjects (combined of regulation, utilization, appraisal and overall EI) across groups (experimental and control groups) regardless of time point $(\mathrm{V}=.494, \mathrm{~F}(4,55)=13.41, \mathrm{p}<$. 001). There is also a significant multivariate effect of training course across within subjects time point (time 1, time2) $(\mathrm{V}=.783, \mathrm{~F}(4,55)=49.63, \mathrm{p}<.001)$. The outcomes of the multivariate tests showed a significant multivariate effect across the interaction effect between groups and time point $(\mathrm{V}=.768, \mathrm{~F}(4,55)=45.55, \mathrm{p}<.001)$. The results of interaction between Time/Groups (pre-post) was significant, $F(4,55)=$ $.78, \mathrm{p}<001$, it showed a composite score of all dependent variables, and also a statistically significant difference between the control and experimental group.

The univariate analyses indicated that regulation of emotion $(\mathrm{F}(1,58)=5.623, \mathrm{p}$ $=.021)$, utilization emotion $(\mathrm{F}(1,58)=26.032, \mathrm{p}<.001)$ and appraisal of emotion $(\mathrm{F}(1,58)=24.949, \mathrm{p}<.001)$ were significantly improved between baseline and the end of training while there was no significant difference between time 1 and time 2 in the control group. Further results showed significant interaction between time and regulation of emotion $(\mathrm{F}(1,58)=12.965, \mathrm{p}<05)$, utilization of emotion $(\mathrm{F}(1,58)=21.086, \mathrm{p}<.001)$, and appraisal of emotion $(\mathrm{F}(1,58)=25.881, \mathrm{p}<$ $.001)$ see Table 3.

Table 3 Univariate $\mathrm{F}$ tests on emotional components 
Zahra Bagheri, Azlina Mohd Kosnin, Mohammad Ali Besharat

\begin{tabular}{|c|l|c|c|c|c|c|}
\hline Source & \multicolumn{1}{|c|}{ Variable } & $\begin{array}{c}\text { Type III Sum } \\
\text { of Squares }\end{array}$ & df & F & Sig & $\begin{array}{c}\text { Partial Eta } \\
\text { Squared }\end{array}$ \\
\hline \multirow{2}{*}{ Time } & $\begin{array}{l}\text { Regulation } \\
\text { Emotion }\end{array}$ & 97.200 & 1 & 5.623 & .021 & .088 \\
\cline { 2 - 7 } & $\begin{array}{l}\text { Utilization } \\
\text { Emotion }\end{array}$ & 333.333 & 1 & 26.032 & .000 & .310 \\
\cline { 2 - 7 } & Appraisal Emotion & 388.800 & 1 & 24.949 & .000 & .301 \\
\hline \multirow{2}{*}{$\begin{array}{c}\text { time } * \\
\text { group }\end{array}$} & $\begin{array}{l}\text { Regulation } \\
\text { Emotion }\end{array}$ & 224.133 & 1 & 12.965 & .001 & .183 \\
\cline { 2 - 7 } & $\begin{array}{l}\text { Utilization } \\
\text { Emotion }\end{array}$ & 270.000 & 1 & 21.086 & .000 & .267 \\
\cline { 2 - 7 } & Appraisal Emotion & 403.333 & 1 & 25.881 & .000 & .309 \\
\hline
\end{tabular}

\section{Discussion}

The aim of the present study was to investigate whetheremotion regulation could be improved among young adults using an emotional intelligence training course. The main finding of this study is that the training group scored significantly on appraisal of emotion, utilization emotion to thought and specially emotion regulation that targeted by the training course in this study but the control group remained unchanged. One of the interesting results of this research is improving emotion regulation skills through training the components of emotional intelligence one by one as well as to link each one to regulate emotion. The other programs that provided to improve emotion regulation focused just on emotion regulation and the strategies related. In the present study, the process of teaching and training emotion regulation started with giving knowledge about emotions, functions of emotions and the role of emotions in interpersonal relationship and cognitive activities. It seems that lack of emotion regulation knowledge is a very important contributor to inability to regulate emotions. Teaching and training appraisal of emotion (including: perception, express and appraise) are the second step in this process. This approach that proposedemotion regulation is possible after recognizing emotion stated also by some researchers(Izard, 2001; Lane, 2000; Mayer et al., 2001). Understanding and utilization emotions were the next components that taught and the last one was emotion regulation. Nelis et al. (2009) mentioned that a variety of emotional abilities and habit formations may be effectively improved by learning process, even by using a relatively short training.

The findings of this research have important theoretical and practical implications. At the theoretical level, the results showed that emotion regulation can be increased 
through intensive training, which is consistent with the claim of Mayer and Salovey (1997) and Goleman (1995), stating that emotional intelligence components increases through teaching and training. At the practical level, the findings are more efficacious than theoretical one because improving emotion regulation can maintain mental health, forming better social relationships and adapting better with stressful situations (Tugade \& Fredrickson, 2007) and difficulties in emotion regulation are associated with mental disorders, including depression (Nolen-Hoeksema et al., 2008; Rottenberg, Gross, \& Gotlib, 2005; John \& Gross, 2004), anxiety (Cisler, Olatunji, Feldner, \& Forsyth, 2010; Mennin et al., 2007) and borderline personality disorder (Linehan, 1993; Lynch, Trost, Salsman, $\&$ Linehan, 2007). To sum up, teaching and training emotion regulation skills are essential for all people particularly students that will be joined the graduate working population (Dacre Pool \& Qualter, 2012) and need to have interpersonal skills and emotional adaptation to gain job opportunities and meet standards of living. It could be one of the goals of universities that provide the opportunities to improve the knowledge, skills, efficacy and capacity related to emotional functioning for their students and prepared them for life after graduation. The present study provided some evidences that support the suggestion of adding emotional functioning lessons into curriculum of all educational institutions.

Further experimental investigations are needed to retest and refine these findings. Other research can be form to replicate the results with a larger sample and different scopes such as students in the other fields and level of education (diploma, postgraduate). In this study data gathered from a single source (participants themselves), using multiple source and other instruments to retest the results proposed in the future research. Teaching and training the training course (EITC) in sessions and times more than the original one is another suggestion. According to experience of researchers in this study, emotion regulation skills need more training and practice to be established in the people. However, results showed an improvement in emotion regulation skills.

\section{References and notes:}

1. Austin, E.J, saklofske. D. H and Egan v. (2005) Personality, well-being and Health Correlates of Trait Emotional Intelligence. Personality and Individual Differences, 38, 547-558.

2. Austin, E. J., Saklofske, D. H., Huang, S. H. S., \& McKenney, D. (2004). Measurement of trait emotional intelligence: testing and cross-validating a modified version of Schutte et al.'s (1998) measure. Personality and Individual Differences, $36,555-562$.

3. Bargh, J. A., \& Williams, L. E. (2007) The case for unconscious emotion regulation. In 
4. J. J. Gross (Ed.), Handbook of emotion regulation (pp. 429-445). New York: Guilford Press

5. Besharat, M. A. (2007). Psychometric properties of Farsi version of the Emotional Intelligence Scale-41 (FEIS-41). Personality and Individual Differences. 43, 9911000 .

6. Brackett,M.A.,\&Salovey, P. (2004). Measuring emotional intelligence as a mental ability with the Mayer-Salovey-Caruso Emotional Intelligence Test. In G. Geher (Ed.), Measurement of emotional intelligence (pp. 179-194). Hauppauge, NY: Nova Science Publishers.

7. Campbell-Sills, L., \& Barlow, D. H. (2007). Incorporating emotion regulation into conceptualizations and treatments of anxiety and mood disorders. In J. J. Gross (Ed.), Handbook of emotion regulation (pp. 542-559). New York: Guilford.

8. Caspi, A. (2000). The child is father to the man: Personality continuities from childhood to adulthood. Journal of Personality and Social Psychology, 78, 158-172.

9. Cisler, J. M., Olatunji, B. O., Feldner, M. T., \& Forsyth, J. P. (2010). Emotion regulation and the anxiety disorders: an integrative review. Journal of Psychopathology and Behavioral Assessment, 32, 68-82.

10. Cole, P. M., Martin, S. E., \& Dennis, T. A. (2004). Emotion regulation as a scientific construct: Methodological challenges and directions for child development research. Child Development, 75, 317-333.

11. Dacre Pool, L. \& Qualter, P. (2012). Improving emotional intelligence and emotional self-efficacy through a teaching intervention for university students.

Learning and Individual Differences 22 (2012) 306-312.

12. Damasio, A. R. (1994). Descartes' error: Emotion, Reason and the Human brain. Grosset/ Putnam. New York: Grosset/Putnam.

13. Dawda, D., \& Hart, S. D. (2000). Assessing emotional intelligence: Reliability and validity of the Bar-On Emotional Quotient Inventory (EQ-i) in university students. Personality and Individual Differences, 28, 797-812.

14. Day, A.L., Therrien, D.L., \& Carroll, S.A. (2005). Predicting psychological health: Assessing the incremental validity of emotional intelligence beyond personality, type A behaviour, and daily hassles. European Journal of Personality, 19, 519-536.

15. Denham, S. A., \& Burton, R. (2003). Social and emotional prevention and intervention programs for preschoolers. New York, NY: Kluwer-Plenum.

16. Dorota Szczygiel, J. Buczny, \& R. Bazinska (2011). Emotion regulation and emotional information processing: The moderating effect of emotional awareness.Personality and Individual Differences 52 (2012) 433-437

17. Eisenberg, N., Fabes, R. A., Guthrie, I. K., \& Reiser, M. (2000). Dispositional emotionality and regulation: their role in predicting quality of social functioning. Journal of Personality and Social Psychology, 78, 136-157.

18. Furnham, A., \& Petrides, K. V. (2003). Trait emotional intelligence and happiness. Social Behavior and Personality, 31, 815-823.

19. Goleman, D. (1995). Emotional intelligence. New York: Bantam Books.

20. Greenberg, L. S. (2002). Emotion-focused therapy: Coaching clients to work through their feelings. Washington, DC, US: American Psychological Association. 
21. Gross, J. J. (1998). The emerging field of emotion regulation: An integrative review. Review of General Psychology, 2, 271-299.

22. Gross, J. J., \& John, O. P. (2003). Individual differences in two emotion regulation processes: Implications for affect, relationships, and well-being. Journal of Personality and Social Psychology, 85, 348-362.

23. Gross, J. J., \& Muñz, R. F. (1995). Emotion regulation and mental health. Clinical Psychology: Science and Practice, 2, 151-164.

24. Gumora, G., \& Arsenio, W. F. (2002). Emotionality, emotion regulation, and school

25. performance in middle school children. Journal of School Psychology, 40 (5), 395413.

26. Izard, C. E. (2001). Emotional intelligence or adaptive emotions? Emotion, 3, 249257.

27. John, O. P., \& Gross, J. J. (2004). Healthy and unhealthy emotion regulation: Personality processes, individual differences, and life span development. Journal of Personality, 72 (6), 1301-1333.

28. Kun, B., \& Demetrovics, Z. (2010). Emotional intelligence and addictions: A systematic

29. review. Substance Use \& Misuse, 45 (7-8), 1131-1160.

30. Lane, R. D. (2000). Levels of emotional awareness. In R. Bar-On, \& J. D. A. Parker (Eds.), The handbook of emotional intelligence (pp. 171-191). San Francisco: Jossey-Bass.

31. Linehan, M. M. (1993). Cognitive behavioral treatment of borderline personality disorder. New York, NY: Guilford Press.

32. Lotze, G. M., Ravindran, N., \& Myers, B. J. (2010). Moral emotions, emotion selfregulation, callous-unemotional traits, and problem behavior in children of incarcerated mothers. Journal of Child and Family Studies, 19, 702-713.

33. Lynch, T. R., Trost, W. T., Salsman, N., \& Linehan, M. M. (2007). Dialectical behavior therapy for borderline personality disorder. Annual Review of Clinical Psychology, 3, 181-205.

34. Martins, A., Ramalho, N., \& Morin, E. (2010). A comprehensive meta-analysis of the relationship between emotional intelligence and health. Personality and Individual Differences, 49, 554-564, doi:10.1016/j.paid.2010.05.029.

35. Mayer, J. D., \& Salovey, P. (1997). What is emotional intelligence? In P. Salovey \& D. J.

36. Sluyter (Eds.), Emotional development and emotional intelligence (pp. 3-31). New York, NY: Basic Books.

37. Mayer, J. D., Salovey, P., Caruso, D. R., \& Sitarenios, G. (2001). Emotional intelligence as a standard intelligence. Emotion, 3, 232-242.

38. Mennin, D. S., Holoway, R. M., Fresco, D. M., Moore, M. T., \& Heimberg, R. G. (2007). Delineating components of emotion and its deregulation in anxiety and mood psychopathology. Behavior Therapy, 38, 284e302.

39. Mennin, D., \&Farach, F. (2007). Emotion and evolving treatments for adult psychopathology. Clinical Psychology: Science and Practice, 14, 329-352. 
40. Mennin, D.S., \& Fresco, D.M. ( 2009). Emotion regulation as an integrative framework for understanding and treating psychopathology. In A. M. Kring \& D. S. Sloan (Eds.), Emotion regulation and psychopathology: A transdiagnostic approach to etiology and treatment (pp. 356-379). New York: Guilford Press.

41. Metcalfe, J., \& Mischel, W. (1999). A hot/cool system analysis of delay of gratification: Dynamics of willpower. Psychological Review, 106, 3-19.

42. Nelis, D., Quoidbach, J., Mikolajczak, M., \& Hansenne, M. (2009). Increasing emotional

43. intelligence: (How) is it possible? Personality and Individual Differences, 47, 3641, doi:10.1016/j.paid2009.01.046.

44. Nolen-Hoeksema, S., Wisco, B. E., \& Lyubomirsky, S. (2008). Rethinking rumination.

45. Perspectives on Psychological Science, 3, 400-424.

46. Palmer, B. R., Donaldson, C., \& Stough, C. (2002). Emotional intelligence and life satisfaction. Personality and Individual Differences, 33, 1091-1100.

47. Rottenberg, J., \& Gross, J. J. (2003). When emotion goes wrong: Realizing the promise of affective science. Clinical Psychology Science and Practice, 10, 227-232.

48. Rottenberg, J., Gross, J. J., \& Gotlib, I. H. (2005). Emotion context insensitivity in major

49. depressive disorder. Journal of Abnormal Psychology, 114, 627-639.

50. Saklofske, D. H., Austin, E. J., \& Minski, P. (2003). Factor structure and validity of a trait emotional intelligence measure. Personality and Individual Differences, 34, 707-721.

51. Salovey, P., \& Mayer, J. (1990) Emotional intelligence Imagination, cognition, and personality, 9(3), 185-211.

52. Schutte NS, Malouff JM, Hall LE, Haggerty DJ, Cooper JT, Golden CJ, et al. Development and validation of a measure of emotional intelligence. Personality and Individual Differences 1998; 25: 167- 177.

53. Thompson, R. A. (1994). Emotion regulation: a theme in search of definition. Monographs of the Society for Research in Child Development, 59, 24-52 (2-3; Serial No. 240).

54. Tugade, M.M., \& Fredrickson, B.L. (2007). Regulation of positive emotions: Emotion regulation strategies that promote resilience. Journal of Happiness Studies, 8, 311-333. 


\section{Appendix A}

Outline of emotional intelligence training course

Session 1: Introductions

$>$ Briefing workshop (Schedule program: dates, timetable, number of sessions and rules such as students should be participate in all sessions)

$>$ Description of the sessions and explain how to use the personal diary

$>$ Definition of emotions

$>$ Functioning of emotions (physiological and neurological)

$>$ Providing a list of emotions with participants

$>$ Explanation the role of emotions in all activities in everyday life

Session 2: Emotion perception

$>$ Definition of perception emotion

$>$ Explanation the process of emotion perception and emotion expression in own and others

$>$ How to express emotions via face, voice and body language

Session 3: Understanding emotion

$>$ Definition of Understanding emotion

$>$ Explanation the complex emotion

$>$ Explanation the chain of emotions (the transition of emotions, and how one leads to another such as stress leads to fear, fear leads to anger and anger leads to hate)

Session 4: Using emotion to facilitate thought

$>$ Definition of using emotion

$>$ How emotions affect cognitive activities (decision making and solving problems)

$>$ Explanation the decision making process

$>$ Explanation the problem solving process

Session 5: Managing emotions 1

$>$ Definition of emotion regulation

$>$ Explanation the role of emotion regulation in intrapersonal and interpersonal skills

$>$ Strategies to regulation emotion and their effectiveness

$>$ Relationship between emotion regulation and other components of EI

Session 6: Managing emotions 2

Relaxation techniques for control negative emotions (stress, anxiety, anger)

$>$ Training Relaxation exercises

$>$ Explanation the role of aerobic exercise (walking, jogging, distance running, swimming and cycling) on control negative emotion 


\title{
Summary
}

\section{Improving Emotion Regulation skills through an Emotional Intelligence Training Course}

\author{
Zahra Bagheri, \\ Universiti Teknologi Malaysia, Johor, Malaysia \\ Azlina Mohd Kosnin, \\ Universiti Teknologi Malaysia, Johor, Malaysia \\ Mohammad Ali Besharat \\ University of Tehran, Iran
}

Emotion regulation is the fourth component of emotional intelligence theory introduced by Salovey and Mayer (1990). It has received much interest in recent years due to its significant effect on life qualities such as mental health, social relationship, academic achievement and work performance. However, there were not enough empirical studies to examine whether the training of emotional intelligence can improve emotion regulation skills. This paper describes a quasi-experimental study aimed at answering the question, 'Does training in emotional intelligence create more emotionally intelligent behavior, particularly emotion regulation?' Emotional intelligent behavior was measured by responses to a written test (FEIS-41) in twice, before and after the training course. The subject participants were 60 and divided into an experimental group and a control group. The experimental group received an emotional intelligence training course, while the control group did not. The training course had six sessions, held once per week for two and a half hours. The results showed that the level of emotion regulation improved in the experimental group after the emotional intelligence training.

Keywords: emotional intelligence, quasi-experimental study, emotion regulation, an experimental and a control group, emotional processing 